ARTICLE

\title{
Modular synthesis of chiral 1,2-dihydropyridines via Mannich/Wittig/cycloisomerization sequence that internally reuses waste
}

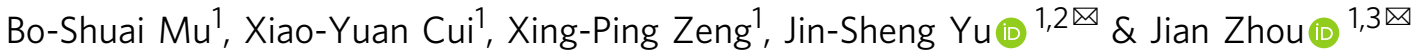

1,2-Dihydropyridines are valuable and reactive synthons, and particularly useful precursors to synthesize piperidines and pyridines that are among the most common structural components of pharmaceuticals. However, the catalytic enantioselective synthesis of structurally diverse 1,2-dihydropyridines is limited to enantioselective addition of nucleophiles to activated pyridines. Here, we report a modular organocatalytic Mannich/Wittig/cycloisomerization sequence as a flexible strategy to access chiral 1,2-dihydropyridines from $\mathrm{N}$-Boc aldimines, aldehydes, and phosphoranes, using a chiral amine catalyst. The key step in this protocol, cycloisomerization of chiral $N$-Boc $\delta$-amino $\alpha, \beta$-unsaturated ketones recycles the waste to improve the yield. Specifically, recycling by-product water from imine formation to gradually release the true catalyst $\mathrm{HCl}$ via hydrolysis of $\mathrm{SiCl}_{4}$, whilst maintaining a low concentration of $\mathrm{HCl}$ to suppress side reactions, and reusing waste $\mathrm{Ph}_{3} \mathrm{PO}$ from the Wittig step to modulate the acidity of $\mathrm{HCl}$. This approach allows facile access to enantioenriched 2substituted, 2,3- or 2,6-cis-disubstituted, and 2,3,6-cis-trisubstituted piperidines.

\footnotetext{
${ }^{1}$ Shanghai Engineering Research Center of Molecular Therapeutics and New Drug Development, Shanghai Key Laboratory of Green Chemistry and Chemical Processes, East China Normal University, Shanghai 200062, China. ${ }^{2}$ Key Laboratory of Tropical Medicinal Resource Chemistry of Ministry of Education, Hainan Normal University, Haikou 571158, China. ${ }^{3}$ State Key Laboratory of Organometallic Chemistry, Shanghai Institute of Organic Chemistry, CAS,

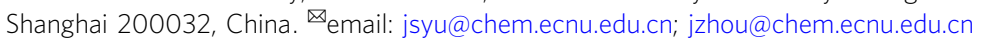


P iperidines and pyridines are among the most important azacycles present in pharmaceutically active compounds, drugs, and agrochemical targets (Fig. 1a) ${ }^{1-3}$. They constitute the top two prevalent structural motifs in small-molecule drugs that contain $N$-heterocycles, as revealed by a recent analysis of FDA approved drugs ${ }^{4}$. The facile and economical synthesis of structurally diverse piperidines and pyridines is important for future advances in chemistry, medicine, and biology. Despite intensive studies and significant achievements ${ }^{5-7}$, the predictable and modular assembly of substituted piperidines in high diastereomeric excess (de) and enantiomeric excess (ee) from readily available starting materials, using inexpensive chiral catalysts, remains a challenge; the tailor-made metal-free synthesis of substituted pyridines with high chemo- and regioselectivity are also limited ${ }^{5}$. In this context, the 1,2-dihydropyridines are common precursors for the synthesis of piperidines or pyridines, via reduction or oxidation, respectively. Furthermore, they are versatile building blocks for the synthesis of complex molecules ${ }^{8-10}$ and natural products ${ }^{11,12}$.

Nevertheless, the efficient and economical synthesis of optically active 1,2-dihydropyridines with high structural diversity remains undeveloped $^{13,14}$. Several enantioselective methods have been developed, on the basis of three major approaches (Fig. 1b). Traditional strategies using stoichiometric amounts of chiral sources, either in the step-wise synthesis from chiral amine derivatives or diastereoselective functionalization of pyridines with chiral auxiliaries, usually require tedious multistep reaction processes $^{15-17}$. Since the pioneering work of Shibasaki et al. ${ }^{18}$, the enantioselective addition of nucleophiles to activated pyridines, such as pyridinium salts, has emerged as an attractive method ${ }^{12,18-24}$. However, this strategy requires control of the regioselectivity of the attack at $\mathrm{C} 2 / \mathrm{C} 4$ position ${ }^{13}$ and it suffers from limited substitution patterns.

Here, we report an organocatalytic strategy for the modular synthesis of chiral 1,2-dihydropyridines from readily available starting materials, namely, a Mannich/Wittig/cycloisomerization sequence (Fig. 1c) ${ }^{25}$. This approach takes advantage of the proline-catalyzed Mannich reaction of $\mathrm{N}$-Boc imines and aldehydes, established by List and coworkers ${ }^{26-28}$, to induce a very high level of asymmetry. Advantages expected from this strategy include the use of inexpensive chiral catalysts, achieving high structural diversity by varying the substituents of each substrate, no contamination from transition metals, and the use of an easily removable Boc protecting group.

\section{Results}

Proof-of-principle study and optimization of the reaction conditions. The success of this strategy relies on exploiting a cycloisomerization of chiral $\delta$-amino $\alpha, \beta$-unsaturated ketones $\mathbf{1}$ to obtain 1,2-dihydropyridines. The condensation of amines with ketones usually takes place under acid catalysis ${ }^{29}$. However, with a bulky acid-sensitive $\mathrm{N}$-Boc protecting group, the cycloisomerization of $\mathbf{1}$ deemed to be not easy. There appears to be only one earlier report on a similar transformation; Donohoe et al. utilized a stoichiometric amount of trifluoroacetic acid (TFA) to promote the cycloisomerization of racemic $N$-tosyl $\delta$-amino enones without a $\gamma$-substituent, at $80^{\circ} \mathrm{C}^{30}$. In our study, the use of $100 \mathrm{~mol} \%$ TFA to mediate the cycloisomerization of $1 \mathrm{a}$ at 80 or $40^{\circ} \mathrm{C}$ for $10 \mathrm{~h}$ resulted in ca. $7 \%$ NMR yield of target $2 \mathrm{a}$, with $63 \%$ or $37 \%$
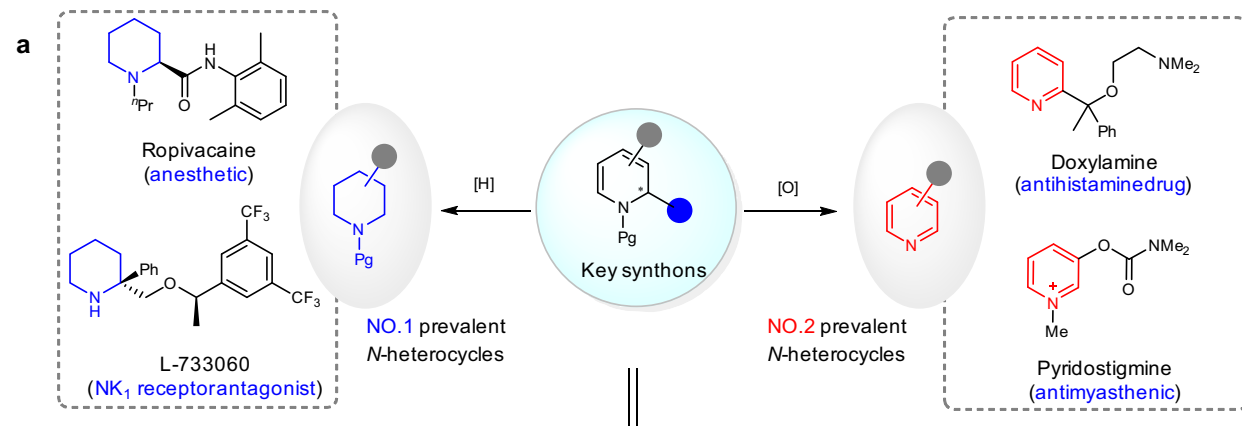

b

Known strategies
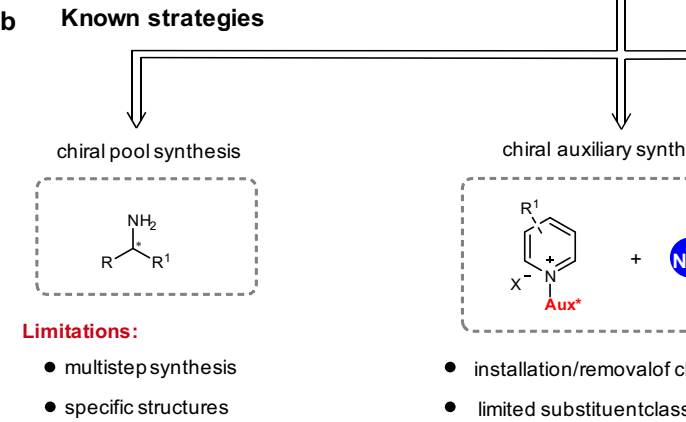

chiral auxiliary synthesis

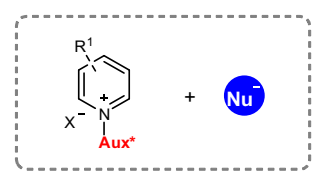

- installation/removalof chiral auxiliary

- limited substituentclasses
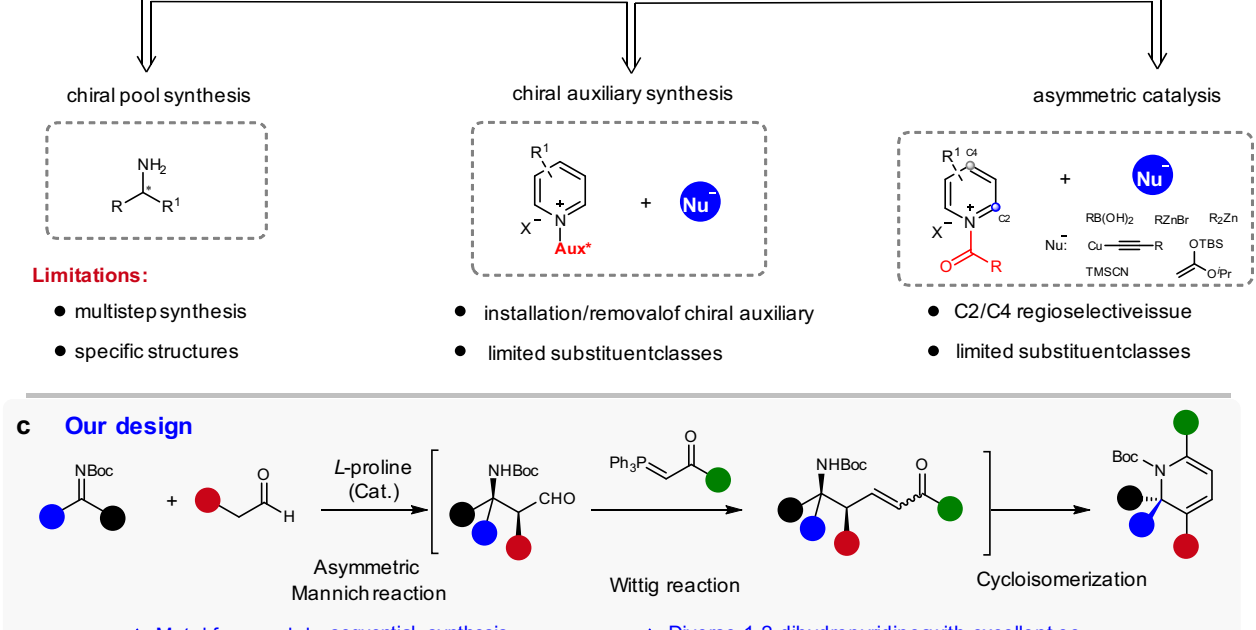

- Diverse 1,2-dihydropyridineswith excellent ee

Fig. 1 Reaction development. a Selected drugs featuring a piperidine or pyridine core. b Known strategies to chiral 1,2-dihydropyridines. c Organocatalytic Mannich/Wittig/cycloisomerization sequence to chiral 1,2-dihydropyridines. 


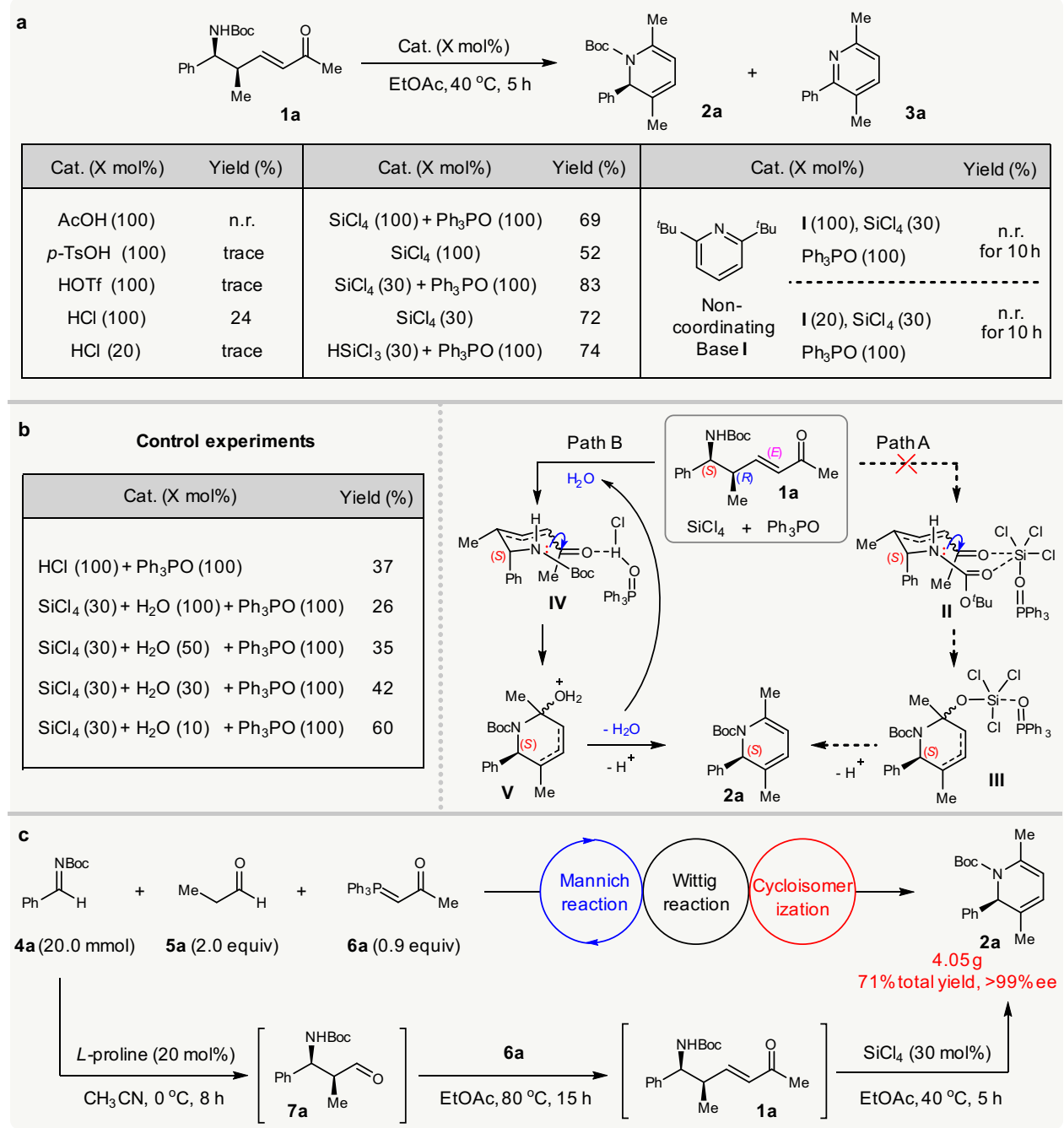

Fig. 2 Proof-of-principle study. a Optimization of conditions for the cycloisomerization of 1a. b Control experiments and possible mechanism. c Gramscale asymmetric Mannich/Wittig/cycloisomerization sequence. Boc: tert-butyloxycarbonyl. EtOAc: ethyl acetate.

conversion of $1 \mathbf{a}$ and $33 \%$ or $14 \%$ NMR yield of pyridine byproduct 3a (see Supplementary Table 1 for details) due to the deprotection of the $N$-Boc group (Fig. 2a).

Further screening of typical Brønsted acids revealed that only $\mathrm{HCl}$ could promote the reaction to give the desired $2 \mathrm{a}$ in $24 \%$ isolated yield, along with $3 a$ in $46 \%$ NMR yield. The generation of 3a should be achieved due to $N$-Boc deprotection, but almost no reaction occurred when using $20 \mathrm{~mol} \% \mathrm{HCl}$. To suppress the side deprotection, it was therefore necessary to identify a milder acid catalyst. Despite several efforts, including the use of more than 20 metal salts, no mediation of this cycloisomerization was achieved (see Supplementary Tables 1 and 2 for details of optimization). Then, inspired by the advances in Lewis base activation of $\mathrm{SiCl}_{4}$ for carbonyl transformations ${ }^{31}$, we tried the use of $\mathrm{SiCl}_{4}$ to mediate the reaction, since our designed tandem sequence will stoichiometrically produce $\mathrm{Ph}_{3} \mathrm{PO}$. Pleasingly, the merger of $\mathrm{SiCl}_{4}$ and $\mathrm{Ph}_{3} \mathrm{PO}$ (each $100 \mathrm{~mol} \%$ ) mediated the reaction to afford $2 \mathrm{a}$ in $69 \%$ yield, which was further improved to $83 \%$ if reducing the $\mathrm{SiCl}_{4}$ to $30 \mathrm{~mol} \%$. The presence of $\mathrm{Ph}_{3} \mathrm{PO}$ benefitted the yield, since the use of $100 \mathrm{~mol} \%$ or $30 \mathrm{~mol} \% \mathrm{SiCl}_{4}$ alone resulted in lower yields of $2 \mathrm{a}$. The merger of $\mathrm{HSiCl}_{3}$ with $\mathrm{Ph}_{3} \mathrm{PO}$ also led to the formation of chiral $\mathbf{2 a}$ in $74 \%$ yield, and no conjugate reduction of enone 1a occurred ${ }^{32}$.

The high yield achieved from the combination of $\mathrm{SiCl}_{4}$ and $\mathrm{Ph}_{3} \mathrm{PO}$ in this cycloisomerization prompted us to then study the reaction mechanism. Based on available knowledge, two possible roles of $\mathrm{SiCl}_{4}$ could be rationalized, despite it waits for further studies when and how the alkene isomerization proceeds (Fig. 2b). One is that it serves as a Lewis acid catalyst, activated by Lewis base $\mathrm{Ph}_{3} \mathrm{PO}$, to promote the reaction (path $\mathrm{A}$ ), and the other is that it acts as a hidden Brønsted acid ${ }^{33-35}$, releasing $\mathrm{HCl}$ as the true catalyst via hydrolysis (path $\mathrm{B}$ ), since $\mathrm{HCl}$ could mediate the reaction as well (Fig. 2b). However, it was found that the addition of either 0.2 or 1.0 equiv of noncoordinating base 2,6-di-tertbutylpyridine terminated the reaction, and ${ }^{29} \mathrm{Si} \mathrm{NMR}$ analysis showed almost no interaction between it and $\mathrm{SiCl}_{4}$ (see Supplementary Fig. 1 for details). These findings implied that the $\mathrm{HCl}$ generated via the hydrolysis of $\mathrm{SiCl}_{4}$ was the true catalyst. Furthermore, it was found that the addition of $10,30,50$, and 100 mol\% $\mathrm{H}_{2} \mathrm{O}$ to the reaction mediated by $30 \mathrm{~mol} \% \mathrm{SiCl}_{4}$ and 1.0 equiv $\mathrm{Ph}_{3} \mathrm{PO}$ led to a gradually decreased yield of $\mathbf{2 a}$. Similarly, using $100 \mathrm{~mol} \% \mathrm{HCl}$ as the catalyst led to only $37 \%$ yield in the presence of $\mathrm{Ph}_{3} \mathrm{PO}$. This implied that the more $\mathrm{HCl}$ present at the initial stage of the reaction, the lower the yield of 2 a due to more side deprotection. These findings agreed with the concept of hidden Brønsted acid catalysis, as the gradual generation of $\mathrm{HCl}$ from $\mathrm{SiCl}_{4}$ inhibited side deprotection to improve the yield. In this cycloisomerization, the hydrolysis of $\mathrm{SiCl}_{4}$ by the trace $\mathrm{H}_{2} \mathrm{O}$ in the reaction system produced $\mathrm{HCl}$ to initiate the reaction, and the subsequent dehydration generated $\mathrm{H}_{2} \mathrm{O}$ that was internally 
used to hydrolyze $\mathrm{SiCl}_{4}$ (Fig. 2b). Such reuse of the by-product $\mathrm{H}_{2} \mathrm{O}$ for the gradual generation of $\mathrm{HCl}$ as the reaction proceeded meant that the concentration of $\mathrm{HCl}$ was kept at a low level, which effectively suppressed side reactions. The role of $\mathrm{Ph}_{3} \mathrm{PO}$ in improving the yield was possibly due to its acid-base interaction with $\mathrm{HCl}$, which modulated the acidity of $\mathrm{HCl}$, as confirmed by ${ }^{31}$ P NMR analysis (see Supplementary Figs. 2 and 3 for details).

Having established the conditions for the key cycloisomerization step, we next integrated it with the proline-catalyzed Mannich/Wittig reaction into a tandem sequence. The procedure finally proved to be convenient. The Mannich reaction of aldimine $\mathbf{4 a}$ and propanal $5 \mathbf{a}$ mediated by $20 \mathrm{~mol} \% \mathrm{~L}$-proline was performed in MeCN. On completion of this reaction, the crude solid adduct $7 \mathbf{a}$ was easily collected and subjected to the reaction with phosphorane $\mathbf{6 a}$ in EtOAc at $80{ }^{\circ} \mathrm{C}$. Once the synthesis of $N$-Boc $\delta$-amino enone 1a was completed, $30 \mathrm{~mol} \%$ $\mathrm{SiCl}_{4}$ was directly added to facilitate the cycloisomerization, at 40 ${ }^{\circ} \mathrm{C}$. Remarkably, this sequence could be run at a $20 \mathrm{mmol}$ scale, giving 1,2-dihydropyridine 2 a $(4.05 \mathrm{~g})$ in $71 \%$ overall yield and $>99 \%$ ee (Fig. 2c).

Notably, this sequence constitutes a rare example of an asymmetric tandem reaction that internally recycles waste to facilitate the downstream step ${ }^{36-47}$ : by-product water from the imine formation step was reused to produce the true catalyst $\mathrm{HCl}$ and waste $\mathrm{Ph}_{3} \mathrm{PO}$ from the Wittig step was recycled as a modulator. In particular, the gradual reuse of byproduct with the proceeding of the reaction, to generate the true catalyst in situ at a low concentration to suppress side reactions, is unknown. This suggests such sustainable sequential reactions are worthwhile to explore.

Scope of asymmetric Mannich/Wittig/cycloisomerization sequence. Next, the generality of the synthesis of 2,3,6-trisubstituted chiral 1,2-dihydropyridines with respect to differently substituted imines, aldehydes, and phosphoranes was determined (Fig. 3a). A wide range of aryl $\mathrm{N}$-Boc aldimines were compatible with the sequence with propanal $\mathbf{5 a}$ and acetone-derived ylide $\mathbf{6 a}$. Regardless of the nature and position of the substituent on the phenyl ring, the desired adducts $2 \mathbf{b}-\mathbf{i}$ were obtained in $43-63 \%$ yields with $96->99 \%$ ee. 2-Naphthyl-, 2-thienyl-, and 2-furanylsubstituted $\mathrm{N}$-Boc aldimines also readily afforded the desired products $2 \mathbf{j}-\mathbf{l}$ in $56-66 \%$ yields with $98 \%$ ee. The scope of aldehydes $\mathbf{5}$ was satisfactory; the targets $\mathbf{2 m - y}$ were obtained in $48-70 \%$ yields with $92->99 \%$ ee. This enabled the facile incorporation of diverse substituents on the C3 position of chiral 1,2dihydropyridines (including aryl, alkyl, allyl, and (methylthio) methyl groups)-offering the hope of further modification. Moreover, $a$-imino ester was a viable substrate ${ }^{48}$; it afforded 2ethylcarboxylate-substituted 1,2-dihydropyridines $\mathbf{8 a - c}$ in $33-65 \%$ yields with $89-92 \%$ ee. Ethyl-, propyl-, and phenylsubstituted phosphoranes $\mathbf{6}$ were also tolerated under optimized conditions, giving the 2,3,6-trisubstituted dihydropyridines 8d-f in moderate yields with $93-99 \%$ ee. This permitted a variation of the C6 substituent of the products.

The modular synthesis of enantioenriched 2,3- and 2,6disubstituted 1,2-dihydropyridines was also achieved by using acetaldehyde-derived ylide $\mathbf{6}$ or/and acetaldehyde, as demonstrated by the preparation of $\mathbf{9 a - 1}$ with $86->99 \%$ ee (Fig. 3b). As anticipated, the sequence in which use was made of $N$-Boc aldimines, acetaldehyde-derived ylide $\mathbf{6}$, and acetaldehyde $\mathbf{5}$ enabled the smooth preparation of $N$-Boc 2-aryl-substituted 1,2dihydropyridines 10a,b in $32-42 \%$ yields with $97-99 \%$ ee (Fig. 3c). Remarkably, the isatin-derived $\mathrm{N}$-Boc ketimines have emerged as useful substrates, as well as in the current sequence ${ }^{49}$, affording the valuable chiral dihydropyridine-based spirooxindoles 11a-e featuring a tetrasubstituted carbon stereocenter with $85-88 \%$ ee, albeit in modest yields (Fig. 3d).

Synthetic utility. This sequence was further extended for the synthesis of polysubstituted pyridines, because the addition of $\mathrm{MeOH}$ to quench the remaining $\mathrm{SiCl}_{4}$ and its hydrolyzed derivatives would release $\mathrm{HCl}$ that could be reused for $N$-Boc deprotection $^{50}$. The resulting unprotected 1,2-dihydropyridines could then be easily oxidized to afford pyridines ${ }^{51}$. Interestingly, the tunable synthesis of both pyridines and 3-hydroxyl pyridines was achieved by varying the quenching procedures (See the Supplementary Information for details). More importantly, the synthetic value of this protocol was highlighted by the diverse product transformations. First, the thus obtained structurally diverse enantioenriched 1,2- dihydropyridines could be used for the facile synthesis of piperidines with one, two, or three stereocenters, via hydrogenation, using $\mathrm{Pd} / \mathrm{C}$ or $\mathrm{PtO}_{2} \cdot \mathrm{H}_{2} \mathrm{O}$ as the catalyst (Fig. 4a). For example, N-Boc 2,3,6-cis-trisubstituted piperidines 12a-l were obtained in $75-99 \%$ yields, and with $5: 1$ to $>20: 1 \mathrm{dr}$ and $87->99 \%$ ee. The relative and absolute configuration of product $\mathbf{1 2} \mathbf{j}$ was assigned based on its hydrochloride 13 . These piperidines had substantial structural diversity, because the C2 substituent could be a phenyl, 2-furanyl, or ester group, whereas the C3 substituent could be an aryl or aliphatic group. It should be mentioned that methods to access chiral C3 substituted azacycles are very limited ${ }^{52}$. Furthermore, optically active cispolysubstituted piperidines are generally difficult to access in excellent ee values ${ }^{53-59}$. Given the importance of piperidines in drug discovery ${ }^{4}$, these chiral piperidines should be very useful/ valuable in medicinal chemistry research.

The 2,6- and 2,3-cis-disubstituted $N$-Boc piperidines could also be readily accessed via the $\mathrm{Pt}_{2} \mathrm{O}$-catalyzed hydrogenation of the corresponding chiral 1,2-dihydropyridines, as exemplified by the facile access to piperidines $\mathbf{1 2} \mathbf{m}-\mathbf{q}$ in $70-95 \%$ yields, and with $12: 1->20: 1 \mathrm{dr}$ and $95->99 \%$ ee values. Furthermore, starting from 2-phenyl dihydropyridine 10a, the corresponding piperidine 12r was obtained in $92 \%$ yield with $99 \%$ ee; it is a key intermediate for $\mathrm{NK}_{1}$ receptor antagonist synthesis ${ }^{60,61}$. Notably, chiral 1,2dihydropyridine 2 a could be selectively reduced to enantioenriched tetrahydropyridine 14 in $74 \%$ yield with $>20: 1 \mathrm{dr}$ and $98 \%$ ee value (Fig. 4b). In addition, upon treatment with $N$ methylmaleimide, chiral 1,2-dihydropyridines $9 \mathrm{~g}$ and $\mathbf{1 0 a}$ could smoothly deliver the corresponding bridged rings $\mathbf{1 5 a}$ and $\mathbf{1 5 b}$ in high yields with excellent $\mathrm{dr}$ and ee values (Fig. $4 \mathrm{c}$ ). The structure and configuration of $\mathbf{1 5 b}$ was confirmed by its X-ray analysis (see Supplementary Table 17 for details).

\section{Discussion}

The ability to modularly assemble 1,2-dihydropyridines from simple substrates efficiently and enantioselectively, using inexpensive and readily available organocatalysts, should have a substantial impact on the accessibility of piperidine derivatives, particularly the otherwise difficult-to-prepare cis-polysubstituted pyridines, for medicinal research. This operationally friendly Mannich/Wittig/cycloisomerization sequence should also lead to its more widespread adoption for the diversity-oriented synthesis of polysubstituted pyridines and 3-hydroxylpyridines. In a broader sense, this research reveals the merit of sustainable tandem reactions that internally reuse waste, and the recycling of gradually produced by-products to generate the true catalyst could keep the concentration of the catalyst at a low level to suppress side reactions. We expect that our findings will inspire the future development of such sustainable sequential reactions for the economical and efficient synthesis of value-added compounds. 

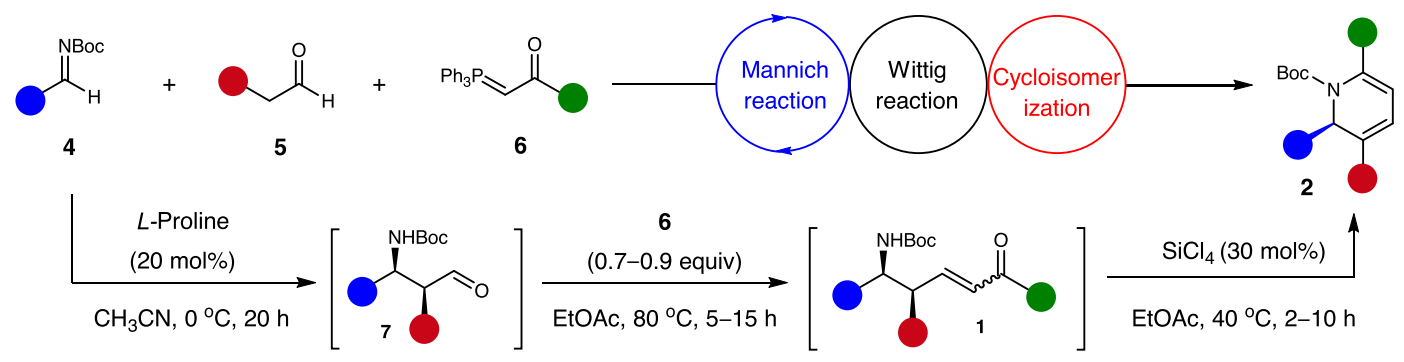<smiles>CC1=CC=C(C)N([18O])C1c1ccc(C)cc1</smiles>

$2 b-2 g$<smiles>CC1=CC=C(C)N(C(=O)OC(C)(C)C)[C@H]1c1cccs1</smiles>

2k, $66 \%^{\star}, 98 \%$ ee<smiles>C=CCC1=CC=C(C)N(C(=O)OC(C)(C)C)C1c1ccccc1</smiles>

2t, $61 \%$ * $99 \%$ ee<smiles>CCOC(=O)[C@@H]1C([N])=CC=C(C)N1C(=O)OCc1ccccc1</smiles>

$8 a, 33 \%$, $89 \%$ ee

b<smiles>CC1=CC=CN(C(=O)OCc2ccccc2)[C@H]1c1ccccc1</smiles>

$9 a, 42 \%$, $98 \%$ ee

c<smiles>O=C(c1ccccc1)N1C=CC=C[C@H]1c1ccccc1</smiles>

$10 a, 42 \%$ *, $97 \%$ ee

\begin{abstract}
2b, R = 4-Me: $63 \%$, >99\% ee
2c, $\mathrm{R}=4-\mathrm{MeO}: 60 \%, 99 \%$ ee

2d, $R=4-F: 45 \%, 99 \%$ ee

2e, $\mathrm{R}=4-\mathrm{Cl}: 56 \%$, >99\% ee

2f, $\mathrm{R}=4-\mathrm{Br}: 55 \%, 96 \%$ ee

2g, R $=4-\mathrm{CF}_{3}: 44 \%$ * $98 \%$ ee
\end{abstract}<smiles>CC1=CC=C([N+](=O)[O-])N(C(=O)OC(C)(C)C)[C@@H]1c1ccco1</smiles>

2I, $56 \%, 98 \%$ ee<smiles>CCCCC(=O)OC(C)(C)C</smiles><smiles>CC1=CC=C([N+](=O)[O-])N(C(=O)OC(C)(C)C)C1c1cccc(Cl)c1</smiles>

2h, $43 \%, 99 \%$ ee

2m, R' $=\mathrm{H}: 52 \%{ }^{\dagger}, 96 \%$ ee

2n, $R^{\prime}=4-\mathrm{Br}: 53 \%{ }^{\dagger}, 97 \%$ ee

2o, $\mathrm{R}^{\prime}=4-\mathrm{Cl}: 55 \%{ }^{\dagger}, 99 \%$ ee

2p, $\mathrm{R}^{\prime}=3-\mathrm{Cl}: 48 \%{ }^{\dagger}, 99 \%$ ee

2q, $\mathrm{R}^{\prime}=2-\mathrm{Cl}: 50 \%{ }^{\dagger}$, >99\% ee<smiles>CC1=CC=C([N+](=O)[O-])N(C(=O)OC(C)(C)C)C1c1ccccc1Cl</smiles>

2i, $49 \%, 97 \%$ ee<smiles>CCC1=CC=C(C)N(C(=O)OC(C)(C)C)[C@H]1c1ccccc1</smiles>

$2 r, 51 \%,>99 \%$ ee<smiles>CC(=O)N1C(C(=O)OC(C)(C)C)=CC=C(C)[C@H]1c1ccc2ccccc2c1</smiles>

2j, $58 \%, 98 \%$ ee<smiles>CC(=O)N1C(C(=O)OC(C)(C)C)=CC=C(Cc2ccccc2)[C@H]1c1ccccc1</smiles>

2s, $60 \%^{\dagger}, 99 \%$ ee<smiles>C=CCC1=CC=C([N+](C)(C)C)N(C(=O)OC(C)(C)C)C1c1ccc(OC)cc1</smiles>

$2 u, 51 \%$ * $99 \%$ ee<smiles>CCOC(=O)[C@@H]1C(Cc2ccccc2)=CC=C([N+](=O)[O-])N1C(=O)OCc1ccccc1</smiles>

8b, $65 \%{ }^{*}, 91 \%$ ee<smiles>CC(C)(C)OC(=O)N1C=CC=C(Br)[C@H]1c1ccccc1</smiles>

9b, 30\%*, $99 \%$ ee<smiles>Cc1ccc([C@H]2C=CC=CN2C(=O)OC(C)(C)C)cc1</smiles>

10b, $32 \%^{\star}$, $99 \%$ ee<smiles></smiles>

2v, $56 \%{ }^{\star}, 91 \%$ ee<smiles>C=CCC1=CC=C([N+](=O)[O-])[C@H](C(=O)OCC)N1C(=O)OC(C)(C)C</smiles>

$8 c, 45 \%{ }^{\star}, 92 \%$ ee<smiles>C=CCC1=CC=CN(C(=O)OC(C)(C)C)[C@H]1c1ccccc1</smiles>

$9 c, 30 \%{ }^{\star},>99 \%$ ee<smiles>COCC1=CC=C(C)N(C(=O)OC(C)(C)C)[C@H]1c1ccccc1</smiles>

2w, $70 \%{ }^{*}, 98 \%$ ee<smiles>CCC1=CC=C(C)[C@H](c2ccccc2)N1C(=O)c1ccccc1</smiles>

$8 d, 46 \%,>99 \%$ ee<smiles>CC(C)(C)OC(=O)N1C=CC=C(c2ccccc2)[C@H]1c1ccccc1</smiles>

9d, $55 \%{ }^{\dagger}, 95 \%$ ee<smiles>CCCC1=CC=C(C)N(C(=O)OC(C)(C)C)[C@H]1c1ccc(C(F)(F)F)cc1</smiles>

$2 x, 56 \%{ }^{\star},>99 \%$ ee<smiles>COc1ccc([C@H]2C(CS(C)(=O)=O)=CC=C(C)N2C(=O)OC(C)(C)C)cc1</smiles>

2y, $70 \%{ }^{\star}, 95 \%$ ee d<smiles>CC1=CC=C[C@]2(C(=O)Nc3ccccc32)N1C(=O)c1ccccc1</smiles>

11a, 39\%*, $85 \%$ ee

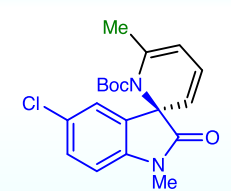

11b, $31 \%^{*}, 87 \% \mathrm{ee}^{\ddagger}$<smiles>CC1=CC=C[C@@H]([Te])N1C(=O)OC(C)(C)C</smiles>

9g, $\mathrm{Ar}=\mathrm{C}_{6} \mathrm{H}_{5}: 63 \%$ *, $98 \%$ ee

9h, $\mathrm{Ar}=4-\mathrm{MeC}_{6} \mathrm{H}_{4}: 45 \%$ *, $95 \%$ ee

9i, $\mathrm{Ar}=4-\mathrm{MeOC}_{6} \mathrm{H}_{4}: 32 \% \%^{\star}, 98 \%$ ee 9j, $\mathrm{Ar}=$ furan: $41 \%{ }^{\star}, 95 \%$ ee<smiles>CCC1=CC=C(C)[C@H](c2ccccc2)N1C(=O)OC(C)(C)C</smiles>

8 e, $44 \%, 99 \%$ ee<smiles>CCOC(=O)[C@@H]1C([N+](=O)[O-])=CC=CN1C(=O)OCc1ccccc1</smiles>

9 e, $20 \%$ *, $86 \%$ ee<smiles>CC1=CC=C(c2ccccc2)N(C(=O)OC(C)(C)C)[C@H]1c1ccccc1</smiles>

8f, $20 \%, 93 \%$ ee<smiles>CCOC(=O)[C@@H]1C(Br)=CC=CN1C(=O)OC(C)(C)C</smiles>

9f, $22 \%{ }^{\star}, 86 \%$ ee

Fig. 3 Scope of asymmetric Mannich/Wittig/cycloisomerization sequence. Reaction conditions. Mannich step: imines 4 ( 0.5 mmol), aldehydes 5 ( 1.0 $\mathrm{mmol}), \mathrm{L}$-proline $(20 \mathrm{~mol} \%), \mathrm{CH}_{3} \mathrm{CN}(10 \mathrm{~mL}), 0{ }^{\circ} \mathrm{C}, 20 \mathrm{~h}$. Wittig step: ylides 6 (1.0 equiv based on the crude 7 ), EtOAc $(2 \mathrm{~mL}), 80^{\circ} \mathrm{C}, 15 \mathrm{~h}$. Cycloisomerization step: $\mathrm{SiCl}_{4}(30 \mathrm{~mol} \%), \mathrm{EtOAc}(2 \mathrm{~mL}), 40^{\circ} \mathrm{C}, 2-10 \mathrm{~h}$. Unless otherwise noted, overall yields for 3 steps are given. Ee values were determined by chiral HPLC analysis. ${ }^{\star}$ These reactions begin from the corresponding isolated chiral $\beta$-amino aldehydes $\mathbf{7}$ and the yields for two steps are given. $\dagger$ Using 1.0 equiv of 5. $\mathrm{f}$ Using $\mathrm{SiCl}_{4}(45 \mathrm{~mol} \%)$ instead of $\mathrm{SiCl}_{4}(30 \mathrm{~mol} \%)$. For details, see the Supplementary Information. a Synthesis of 2,3,6trisubstituted 1,2-dihydropyridines. b Synthesis of 2,3- and 2,6-disubstituted 1,2-dihydropyridines. c Synthesis of 2-substituted 1,2-dihydropyridines.

d Typical examples with isatin-derived $\mathrm{N}$-Boc ketimines. 


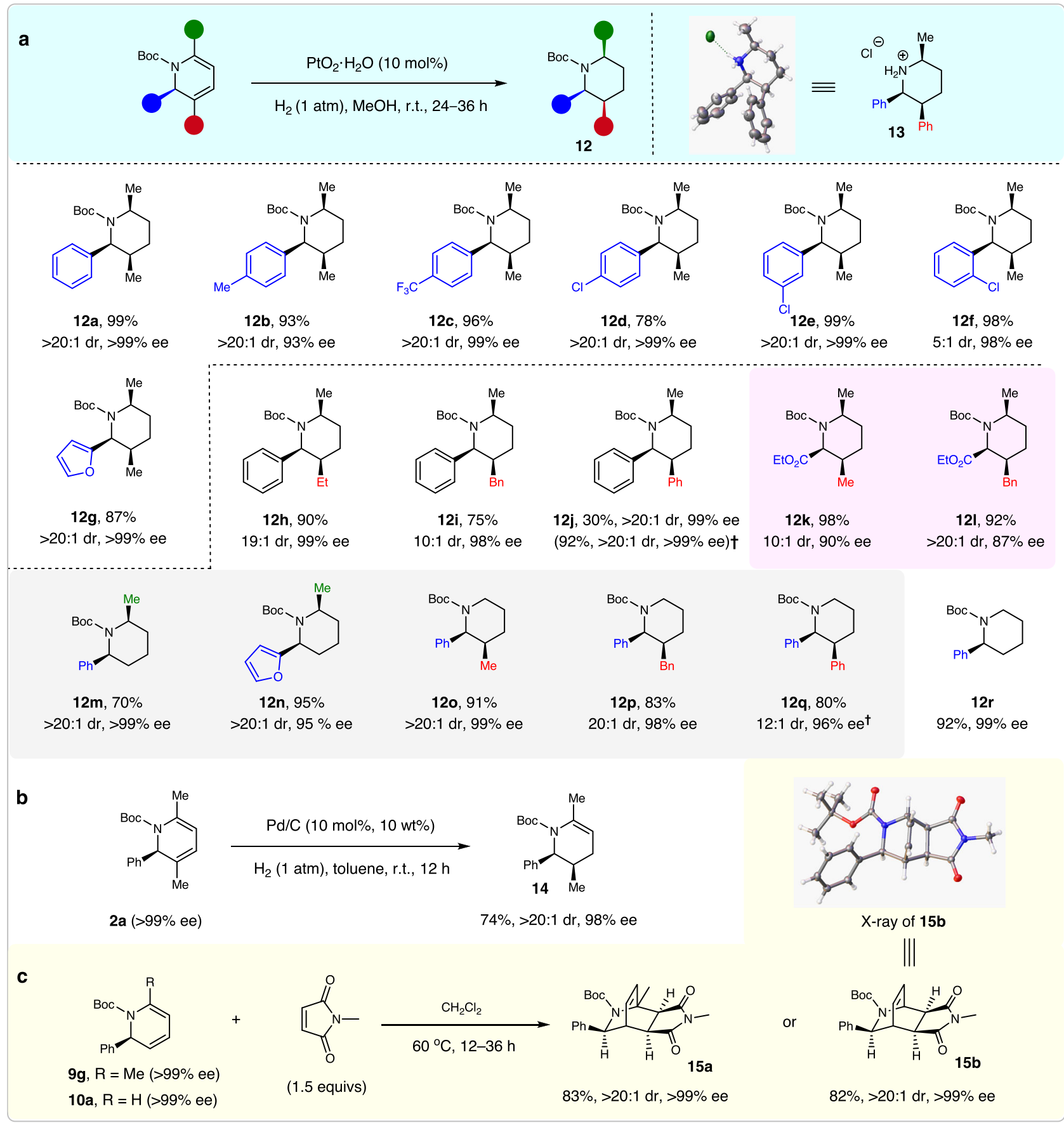

Fig. 4 Synthetic utility. a Diverse synthesis of cis-polysubstituted chiral piperidines 12. b Synthesis of chiral tetrahydropyridine 14. c Diels-Alder reaction to bridged rings 15. †Using $\mathrm{Pd} / \mathrm{C}$ instead of $\mathrm{PtO}_{2} \cdot \mathrm{H}_{2} \mathrm{O}$.

\section{Methods}

General procedure for the Mannich/Wittig/cycloisomerization sequence. Under nitrogen atmosphere, to a $50 \mathrm{~mL}$ flask were added $N$-Boc aldimines $4(0.5 \mathrm{mmol}$, 1.0 equiv), anhydrous acetonitrile $(10.0 \mathrm{~mL})$ and $L$-proline $(11.5 \mathrm{mg}, 0.1 \mathrm{mmol}, 20$ mol\%). The resulting solution was cooled to $0^{\circ} \mathrm{C}$, and the corresponding aldehydes $5(1.0 \mathrm{mmol}, 2.0$ equiv) was added. After being stirred at the same temperature for $20 \mathrm{~h}$, water $(10 \mathrm{~mL})$ was added to the reaction mixture and acetonitrile was evaporated under vacuo. The resulting suspensions was extracted with EtOAc $(10$ $\mathrm{mL} \times 3$ ). The combined organic layers were dried over $\mathrm{Na}_{2} \mathrm{SO}_{4}$, filtered, concentrated and dried under vacuo to afford the crude chiral $\beta$-amino aldehydes 7 as white solid, which was used directly for the next step. To a $10 \mathrm{~mL}$ oven-dried Schlenk tube (with high vacuum valve) was added the above crude aldehydes 7 , phosphorus ylide 6 (1.0 equiv, based on 7), and anhydrous EtOAc ( $2.0 \mathrm{~mL})$. After being stirred at $80^{\circ} \mathrm{C}$ for $15 \mathrm{~h}$ till full conversion of 7 by TLC analysis, $\operatorname{SiCl}_{4}(18 \mu \mathrm{L}$, $0.15 \mathrm{mmol}, 30 \mathrm{~mol} \%$ ) was then added in one portion at ambient temperature, and continued to stir at $40^{\circ} \mathrm{C}$ for $5-10 \mathrm{~h}$ till full conversion of the intermediate $\mathbf{1}$ by
TLC analysis. The reaction mixture was dropwise added to saturated $\mathrm{NaHCO}_{3}$ (aq. $10 \mathrm{~mL})$ at $0{ }^{\circ} \mathrm{C}$ and extracted with EtOAc $(10 \mathrm{~mL} \times 3)$. The combined organic phases were washed with brine, dried over $\mathrm{Na}_{2} \mathrm{SO}_{4}$, and concentrated under reduced pressure to give the residue, which was purified by flash column chromatography using $\mathrm{PE} / \mathrm{Et}_{2} \mathrm{O}(20 / 1, \mathrm{v} / \mathrm{v})$ as the elution to afford the products. Full experimental details and characterization of compounds can be found in the Supplementary Information.

\section{Code availability}

X-ray crystallographic data for compound 3e (CCDC 2018605), 13 (CCDC 2018709) and 15b (CCDC 2044545) are freely available from the Cambridge Crystallographic Data Centre. Copies of the data can be obtained free of charge via https://www.ccdc.cam.ac.uk/ structures/. All other data in support of the findings of this study are available within the Article and its Supplementary Information or from the corresponding author upon reasonable request. 
Received: 15 January 2021; Accepted: 5 March 2021;

Published online: 08 April 2021

\section{References}

1. Taylor, R. D., MacCoss, M. \& Lawson, A. D. G. Rings in drugs. J. Med. Chem. 57, 5845-5859 (2014).

2. Majumdar, K. C. et al. Heterocycles in Natural Product Synthesis (Wiley$\mathrm{VCH}, 2011)$.

3. Alvarez-Builla, J., Vaquero, J. J. \& Barluenga, J. Modern Heterocyclic Chemistry (Wiley-VCH, 2011)

4. Vitaku, E., Smith, D. T. \& Njardarson, J. T. Analysis of the structural diversity, substitution patterns, and frequency of nitrogen heterocycles among U.S. FDA approved pharmaceuticals. J. Med. Chem. 57, 10257-10274 (2014).

5. Allais, C., Grassot, J.-M., Rodriguez, J. \& Constantieux, T. Metal-free multicomponent syntheses of pyridines. Chem. Rev. 114, 10829-10868 (2014).

6. Henry, G. D. De novo synthesis of substituted pyridines. Tetrahedron 60, 6043-6061 (2004).

7. Nebe, M. M. \& Opatz, T. Synthesis of piperidines and dehydropiperidines: construction of the six-membered ring. Adv. Heterocycl. Chem. 122, 191-244 (2017).

8. Yedoyan, J., Wurzer, N., Klimczak, U., Ertl, T. \& Reiser, O. Regio- and stereoselective synthesis of functionalized dihydropyridines, pyridines, and $2 \mathrm{H}$-pyrans: Heck coupling of monocyclopropanated heterocycles. Angew. Chem. Int. Ed. 58, 3594-3598 (2019).

9. Trost, B. M. \& Biannic, B. Redox cycloisomerization approach to 1,2 dihydropyridines. Org. Lett. 17, 1433-1436 (2015).

10. Menichetti, A., Berti, F. \& Pineschi, M. Nitroso Diels-Alder cycloadducts derived from $\mathrm{N}$-Acyl-1,2-dihydropyridines as a new platform to molecular diversity. Molecules 25, 563-580 (2020).

11. Silva, E. M. P., Rocha, D. H. A. \& Silva, A. M. S. Diels-Alder reactions of 1,2dihydropyridines: an efficient tool for the synthesis of isoquinuclidines. Synthesis 50, 1773-1782 (2018).

12. Sun, Z., Yu, S., Ding, Z. \& Ma, D. Enantioselective addition of activated terminal alkynes to 1 -acylpyridinium salts catalyzed by $\mathrm{Cu}$-bis(oxazoline) complexes. J. Am. Chem. Soc. 129, 9300-9301 (2007).

13. Bull, J. A., Mousseau, J. J., Pelletier, G. \& Charette, A. B. Synthesis of pyridine and dihydropyridine derivatives by regio- and stereoselective addition to $\mathrm{N}$ activated pyridines. Chem. Rev. 112, 2642-2713 (2012).

14. Silva, E. M. P., Varandas, P. A. M. M. \& Silva, A. M. S. Developments in the synthesis of 1,2-dihydropyridines. Synthesis 45, 3053-3089 (2013).

15. Shono, T., Matsumura, Y., Onomura, O. \& Yamada, Y. A new method for regioselective synthesis of 2-substituted 1-(methoxycarbonyl)-1,2dihydropyridines. Tetrahedron Lett. 28, 4073-4074 (1987).

16. Comins, D. L. et al. Diastereoselective addition of prochiral metallo enolates to chiral 1-acylpyridinium salts. J. Am. Chem. Soc. 121, 2651-2652 (1999).

17. Charette, A. B., Grenon, M., Lemire, A., Pourashraf, M. \& Martel, J. Practical and highly regio- and stereoselective synthesis of 2-substituted dihydropyridines and piperidines: application to the synthesis of (-)-Coniine. J. Am. Chem. Soc. 123, 11829-11830 (2001).

18. Ichikawa, E. et al. New entries in Lewis acid-Lewis base bifunctional asymmetric catalyst: catalytic enantioselective Reissert reaction of pyridine derivatives. J. Am. Chem. Soc. 126, 11808-11809 (2004).

19. Fernández-Ibáñez, M. A., Maciá, B., Pizzuti, M. G., Minnaard, A. J. \& Feringa, B. L. Catalytic enantioselective addition of dialkylzinc reagents to $\mathrm{N}$ acylpyridinium salts. Angew. Chem. Int. Ed. 48, 9339-9341 (2009).

20. Nadeau, C., Aly, S. \& Belyk, K. Rhodium-catalyzed enantioselective addition of boronic acids to N-benzylnicotinate salts. J. Am. Chem. Soc. 133, 2878-2880 (2011).

21. Chau, S. T., Lutz, J. P., Wu, K. \& Doyle, A. G. Nickel-catalyzed enantioselective arylation of pyridinium ions: harnessing an iminium ion activation mode. Angew. Chem. Int. Ed. 52, 9153-9156 (2013).

22. Lutz, J. P., Chau, S. T. \& Doyle, A. G. Nickel-catalyzed enantioselective arylation of pyridine. Chem. Sci. 7, 4105-4109 (2016).

23. Robinson, D. J., Spurlin, S. P., Gorden, J. D. \& Karimov, R. R. Enantioselective synthesis of dihydropyridines containing quaternary stereocenters through dearomatization of pyridinium salts. ACS Catal. 10, 51-55 (2020).

24. Mancheño, O. G., Asmus, S., Zurro, M. \& Fischer, T. Highly enantioselective nucleophilic dearomatization of pyridines by anion-binding catalysis. Angew. Chem. Int. Ed. 54, 8823-8827 (2015).

25. Zhou, J., Mu, B.-S., Cui, X.-Y., Yu, J.-S. \& Zeng, X.-P. Faming Zhuanli Shenqing (2019), CN 110590644 A 20191220.

26. Yang, J. W., Chandler, C., Stadler, M., Kampen, D. \& List, B. Proline-catalysed Mannich reactions of acetaldehyde. Nature 452, 453-455 (2008).
27. Yang, J. W., Stadler, M. \& List, B. Practical Proline-catalyzed asymmetric Mannich reaction of aldehydes with N-Boc-imines. Nat. Protoc. 2, 1937-1942 (2007).

28. Yang, J. W., Stadler, M. \& List, B. Proline-catalyzed Mannich reaction of aldehydes with N-Boc-imines. Angew. Chem. Int. Ed. 46, 609-611 (2007).

29. Jiao, T. et al. Self-assembly in water with $N$-substituted imines. Angew. Chem Int. Ed. 59, 18350-18367 (2020)

30. Donohoe, T. J. et al. Synthesis of 2,4,6-trisubstituted pyridines via an olefin cross-metathesis /Heck-cyclisation-elimination sequence. Chem. Commun. 47, 10611-10613 (2011)

31. Denmark, S. E. \& Beutner, G. L. Lewis base catalysis in organic synthesis. Angew. Chem. Int. Ed. 47, 1560-1638 (2008).

32. Cao, J.-J., Zhou, F. \& Zhou, J. Improving the atom efficiency of the Wittig reaction by a "waste as catalyst/co-catalyst" strategy. Angew. Chem. Int. Ed. 49, 4976-4980 (2010)

33. Wabnitz, T. C., Yu, J.-Q. \& Spencer, J. B. Evidence that protons can be the active catalysts in Lewis acid mediated hetero-Michael addition reactions. Chem. Eur. J. 10, 484-493 (2004).

34. Šolić, I., Lin, H. X. \& Bates, R. W. Testing the veracity of claims of Lewis acid catalysis. Tetrahedron Lett. 59, 4434-4436 (2018).

35. Sletten, E. T., Tu, Y.-J., Schlegel, H. B. \& Nguyen, H. M. Are Brønsted acids the true promoter of metal-triflate-catalyzed glycosylations? A mechanistic probe into 1,2-cis-aminoglycoside formation by nickel triflate. ACS Catal. $\mathbf{9}$, 2110-2123 (2019).

36. Zhou, J. Multicatalyst System in Asymmetric Catalysis (John Wiley \& Sons, 2014).

37. Kinoshita, T., Okada, S., Park, S.-R., Matsunaga, S. \& Shibasaki, M. Sequential Wittig olefination-catalytic asymmetric epoxidation with reuse of waste $\mathrm{Ph}_{3} \mathrm{P}$ (O): application of $\alpha, \beta$-unsaturated $N$-acyl pyrroles as ester surrogates. Angew. Chem. Int. Ed. 42, 4680-4684 (2003).

38. Gao, X.-T. et al. Utilization of $\mathrm{CO}_{2}$ as a $\mathrm{C} 1$ building block in a tandem asymmetric $\mathrm{A}^{3}$ coupling-carboxylative cyclization sequence to 2oxazolidinones. ACS Catal. 7, 8588-8593 (2017).

39. Zeng, X.-P. et al. Activation of chiral (salen)AlCl complex by phosphorane for highly enantioselective cyanosilylation of ketones and enones. J. Am. Chem. Soc. 138, 416-425 (2016).

40. Wei, W. et al. Recycling catalyst as reactant: a sustainable strategy to improve atom efficiency of organocatalytic tandem reactions. Org. Lett. 20, 6559-6563 (2018).

41. Guo, Y. et al. Successive waste as reagent: two more steps forward in a Pinnick oxidation. Org. Lett. 20, 913-916 (2018).

42. Li, D. et al. Asymmetric Mannich reaction and construction of axially chiral sulfone-containing styrenes in one pot from $\alpha$-amido sulfones based on the waste-reuse strategy. Org. Lett. 20, 4959-4963 (2018).

43. Rubio-Presa, R., Pedrosa, M. R., Fernández-Rodríguez, M. A., Arnáiz, F. J. \& Sanz, R. Molybdenum-catalyzed synthesis of nitrogenated polyheterocycles from nitroarenes and glycols with reuse of waste reduction byproduct. Org. Lett. 19, 5470-5473 (2017).

44. $\mathrm{Yu}, \mathrm{T}$.-Y. et al. $\mathrm{PPh}_{3} \mathrm{O}$ as an activating reagent for one-pot stereoselective syntheses of di- and polybrominated esters from simple aldehydes. J. Org. Chem. 81, 2730-2736 (2016).

45. Zhu, F., Xu, P.-W., Zhou, F., Wang, C.-H. \& Zhou, J. Recycle waste salt as reagent: a one-pot substitution/Krapcho reaction sequence to $\alpha$-fluorinated esters and sulfones. Org. Lett. 17, 972-975 (2015).

46. Chen, L., Shi, T.-D. \& Zhou, J. Waste as catalyst: tandem Wittig/conjugate reduction sequence to $a-\mathrm{CF}_{3} \gamma$-keto esters that uses $\mathrm{Ph}_{3} \mathrm{PO}$ as catalyst for the chemoselective conjugate reduction. Chem. Asian J. 8, 556-559 (2013).

47. Lu, J. \& Toy, P. H. Tandem one-pot Wittig/reductive aldol reactions in which the waste from one process catalyzes a subsequent reaction. Chem. Asian J. 6, 2251-2254 (2011)

48. Gianelli, C., Sambri, L., Carlone, A., Bartoli, G. \& Melchiorre, P. Aminocatalytic enantioselective anti-Mannich reaction of aldehydes with in situ generated $\mathrm{N}$-Cbz and $\mathrm{N}$-Boc Imines. Angew. Chem. Int. Ed. 47, 8700-8702 (2008)

49. Dai, J. et al. Chiral primary amine catalysis for asymmetric Mannich reactions of aldehydes with ketimines: stereoselectivity and reactivity. Angew. Chem. Int. Ed. 56, 12697-12701 (2017).

50. Chen, L. et al. Successively recycle waste as catalyst: a one-pot Wittig/1,4reduction/Paal-Knorr sequence for modular synthesis of substituted furans. Org. Lett. 17, 1557-1560 (2015).

51. Yoshida, M., Mizuguchi, T. \& Namba, K. One-pot synthesis of tri- and tetrasubstituted pyridines by sequential ring-opening/cyclization/oxidation of $\mathrm{N}$-arylmethyl 3-aziridinylpropiolate esters. Angew. Chem. Int. Ed. 53, 14550-14554 (2014)

52. Grozavu, A. et al. The reductive $\mathrm{C} 3$ functionalization of pyridinium and quinolinium salts through iridium-catalysed interrupted transfer hydrogenation. Nat. Chem. 11, 242-247 (2019). 
53. González-Gómez, J. C., Medjahdi, M., Foubelo, F. \& Yus, M. Stereoselective $\alpha-$ aminoallylation of aldehydes with chiral tert-butanesulfinamides and allyl bromides. J. Org. Chem. 75, 6308-6311 (2010).

54. Glorius, F., Spielkamp, N., Holle, S., Goddard, R. \& Lehmann, C. W. Efficient asymmetric hydrogenation of pyridines. Angew. Chem. Int. Ed. 43, 2850-2852 (2004).

55. Kita, Y., Iimuro, A., Hida, S. \& Mashima, K. Iridium-catalyzed asymmetric hydrogenation of pyridinium salts for constructing multiple stereogenic centers on piperidines. Chem. Lett. 43, 284-286 (2014).

56. Chen, M.-W., Ye, Z.-S., Chen, Z.-P., Wu, B. \& Zhou, Y.-G. Enantioselective synthesis of trifluoromethyl substituted piperidines with multiple stereogenic centers via hydrogenation of pyridinium hydrochlorides. Org. Chem. Front. 2, 586-589 (2015).

57. Chen, M.-W. et al. Asymmetric hydrogenation of isoquinolines and pyridines using hydrogen halide generated in situ as activator. Org. Lett. 19, 4988-4991 (2017).

58. Rueping, M. \& Antonchick, A. P. Organocatalytic enantioselective reduction of pyridines. Angew. Chem. Int. Ed. 46, 4562-4565 (2007).

59. Tian, J.-J. et al. Borane-catalyzed chemoselective and enantioselective reduction of 2-vinyl-substituted pyridines. Angew. Chem. Int. Ed. 59, 18452-18456 (2020)

60. Xiao, D. et al. Selective benzylic lithiation of $N$-Boc-2-phenylpiperidine and pyrrolidine: expedient synthesis of a 2,2-disubstituted piperidine $\mathrm{NK}_{1}$ antagonist. Tetrahedron Lett. 46, 7653-7656 (2005).

61. Ye, Z. - -S. et al. Iridium-catalyzed asymmetric hydrogenation of pyridinium salts. Angew. Chem. Int. Ed. 51, 10181-10184 (2012).

\section{Acknowledgements}

This work was supported by the National Natural Science Foundation of China (Grant Nos. 21725203 and 21901074), Shanghai Science and Technology Innovation Action Plan (No. 20JC1416900), the Ministry of Education (PCSIRT), and the Fundamental Research Funds for the Central Universities, and the open foundation of Key Laboratory of Tropical Medicinal Resource Chemistry of Ministry of Education (rdzh2020003) are highly appreciated.

\section{Author contributions}

J.Z. conceived the idea; B.-S.M., X.-Y.C., and X.-P.Z. performed the experiments; B.-S.M. and X.-Y.C. collected and analyzed the data. J.-S.Y. and J.Z. directed the project and cowrote the manuscript.

\section{Competing interests}

The authors declare no competing interest.

\section{Additional information}

Supplementary information The online version contains supplementary material available at https://doi.org/10.1038/s41467-021-22374-y.

Correspondence and requests for materials should be addressed to J.-S.Y. or J.Z.

Reprints and permission information is available at http://www.nature.com/reprints

Publisher's note Springer Nature remains neutral with regard to jurisdictional claims in published maps and institutional affiliations.

\begin{abstract}
Open Access This article is licensed under a Creative Common Attribution 4.0 International License, which permits use, sharing, appropriate credit to the original author(s) and the source, provide a link to the Creative Commons license, and indicate if changes were made. The images or other third party material in this article are included in the article's Creative Commons license, unless indicated otherwise in a credit line to the material. If material is not included in the article's Creative Commons license and your intended use is not permitted by statutory regulation or exceeds the permitted use, you will need to obtain permission directly from the copyright holder. To view a copy of this license, visit http://creativecommons.org/ licenses/by/4.0/
\end{abstract}

(C) The Author(s) 2021 